\title{
Isolating visual units in the perception of words and nonwords
}

\author{
GLEN A. TAYLOR \\ University of Wisconsin, Madison, Wisconsin 53706 \\ and \\ TIMOTHY J. MILLER and JAMES F. JUOLA \\ University of Kansas, Lawrence, Kansas 66044
}

\begin{abstract}
In three experiments, reaction times for same-different judgments were obtained for pairs of words, pronounceable nonwords (pseudowords), and unpronounceable nonwords. The stimulus strings were printed either in a single letter case or in one of several mixtures of upper- and lowercase letters. In Experiment 1, the stimuli were common one- and two-syllable words; in Experiment 2, the stimuli included both words and pseudowords; and in Experiment 3, words, pseudowords, and nonwords were used. The functional visual units for each string type were inferred from the effects that the number and placement of letter case transitions had on same reaction time judgments. The evidence indicated a preference to encode strings in terms of multiletter perceptual units if they are present in the string. The data also suggested that whole words can be used as functional visual units, although the extent of their use depends on contextual parameters such as knowledge that a word will be presented.
\end{abstract}

For over a century, the question of how we perceive letter strings, and words in particular, has both fascinated and troubled experimental psychologists. For some, it has seemed obvious that we perceive individual letters and assemble a word from them. Others have maintained that we perceive whole words directly, while still others have postulated intermediate perceptual units such as spelling patterns, syllables, and vocalic center groups (Smith $\&$ Spoehr, 1974). To the casual observer it must seem perplexing that psychologists have been unable to resolve such a seemingly simple issue in favor of one or another alternative. However, many investigations have resulted in conflicting indications of what constitutes the appropriate visual unit in word perception.

It is understandable that there is reluctance to abandon the attempt to identify a single perceptual unit. If more than one perceptual unit is hypothesized, then an adequate model must specify which units exist and how these units are coordinated. The model to which we subscribe is a process model similar to the one proposed by LaBerge and Samuels

Requests for reprints should be addressed to Glen A. Taylor, Wisconsin Research \& Development Center for Cognitive Learning, The University of Wisconsin, $1025 \mathrm{~W}$. Johnson Street, Madison, Wisconsin 53706. This research was supported by NSF Grant BMS74-12801 to the third author. The second author also received support from an undergraduate research participation award from the University of Kansas. Some of the results presented here were also presented at the annual meeting of the Psychonomic Society, Denver, Colorado, November 1975.
(1974). Word recognition begins with feature extraction from an iconic image of the visual display. Visual features, along with information regarding the relative display positions from which these features have been extracted, automatically activate one or more levels of perceptual unit categories in memory. The various perceptual units activated by a visual display are processed in a categorization stage which synthesizes a percept of the display. Similar to the attention-directing mechanism proposed by LaBerge and Samuels, this categorization stage is assumed to have a limited processing capacity which is distributed over the various available inputs. Thus it might attend to whole-word units, deciding among them in classifying the display; or it might assemble syllables, spelling patterns, or individual letters into a percept of the display. The selection of perceptual units of a particular size would depend on this expected utility. We assume that memorial representation of various perceptual units are minimally redundant feature lists (cf. Smith, 1971). Hence, larger units may be activated earlier in feature extraction, because on the average they require fewer features for recognition than do the smaller units that they logically contain. Although decisions based on larger units might be made with less featural information, they could be less accurate than decisions which await full resolution of all the letters in the display. Expectancies about the type of display to be processed would allow reliance on a level or levels of perceptual units which optimize recognition in a given situation. Although we feel that this model 
adequately accounts for the majority of word perception data, other models (cf. Estes, 1975a, b) might also be capable of accounting for past results and those to be presented here. The present experiments therefore are not tests of this particular model but rather arise as implications of it.

The assumption that perceptual units consist of minimal feature lists for groups of letters implies that processing dependencies exist between letters within a perceptual unit. These dependencies will not be observable between letters spanning different perceptual units. This suggests a methodology for determining what perceptual units are functional in perception. If a visual disruption is introduced into a string, then its processing should be disturbed to the extent that the disruption prevents the use of a functional perceptual unit. The processing of a word might be disrupted, for example, by printing the word in an unusual mixture of upper- and lowercase letters. Suppose that a word's syllables were its functional perceptual units. Then the presence of an unusual transition from one letter case to another within a syllable should disturb the processing of that syllable, whereas a case transition between syllables should have no effect. By this reasoning, perceptual identification should be selectively impaired depending on the number and placement of case transitions in a letter string. By experimentally varying the placement of case transitions with respect to various potential perceptual units such as whole words, syllables, spelling patterns, and letters, functional perceptual units should be revealed. If expectancies and perceptual strategies alter the selection of functional perceptual units (as suggested by Aderman \& Smith, 1971, and Schindler, Well, \& Pollatsek, 1974), then it should be possible to affect his selection by manipulating a subject's expectancies about the type of strings to be presented.

The three experiments reported here employed stimuli presented in various mixtures of upper- and lowercase letters. Systematic case mixtures were introduced into the stimuli to assess the size and nature of perceptual units used in the recognition of words; words and pseudowords; and words, pseudowords, and nonwords, respectively, in Experiments 1, 2, and 3. Processing strategy differences were encouraged by altering the context in which the stimuli were presented in Experiments 2 and 3.

\section{EXPERIMENT 1}

In the first experiment, subjects made samedifferent judgments for pairs of successively presented one- and two-syllable words, and reaction time (RT) was measured. The first word in cach pair was printed in either all uppercase or all lowercase letters, and the second word was printed either intact in the opposite case or with one, two, or five internal letter- case transitions. To avoid obscuring the effects of lettercase transition locations with the locations of letter differences, the data of primary interest were the RTs for same judgments.'

The assumption that case transitions within perceptual units are disruptive while case transitions between units are not leads to the following predictions for perception based on whole-word, syllable, spelling pattern, and single-letter units. For wholeword units, the introduction of a single case transition (except perhaps for a capitalized initial letter) should result in a significant disruption. If a single transition completely eliminates the utility of a unit and if whole words are the only functional units, then the number and placement of additional case transitions should have little further disruptive effect. For syllables and spelling patterns, the disiuptive effects of case transitions will depend on the locations of these transitions with respect to the syllables or spelling patterns in the string. The amount of perceptual disruption should not be a function simply of the number of case transitions but of the number falling within separate perceptual units. Placing transitions between units should have little, if any, effect on perception relative to intact displays if syllables or spelling patterns, and not whole words, are the functional units in perception. Because syllables are readily identifiable linguistic units, this prediction is directly testable for syllables. The same is not true for spelling patterns. There is, at present, no procedure for determining the spelling patterns contained in any given letter string. However, since spelling patterns are presumably related to letter clusters within a string, the introduction of case transitions evenly spaced throughout a string should tend to disrupt one spelling pattern per case transition. Thus, in general, if spelling patterns are functional perceptual units, perceptual performance should exhibit a roughly linear decline with the number of case transitions. Finally, the prediction for single-letter perceptual units is simply that there should be little or no effect of case transitions on perception. All case transitions would fall between perceptual units and therefore have little effect on perceptual processing.

\section{Method}

Stimulus materials. Forty-eight common, six-letter words (mean frequency of $175 /$ million; Kučera \& Francis, 1967) were selected and divided into two sets of equal size. Each set contained four subsets. One subset consisted of six one-syllable words, and the remaining subsets each contained six two-syllable words with their syllable boundaries between the second and third letters (2-4), third and fourth letters (3-3), and fourth and fifth letters (4-2), respectively. These words were selected so that mean frequency and number of visually consistent letters (e.g., letters such as $c, s$, and $o$, whose upper- and lowercase forms are the same except for size) were equated in each subset (see Table 1). Syllabification was verified by reference to Webster's Seventh New Collegiate Dictionary (1963).

The two sets of experimental words, which were used primarily 
for same trials, were augmented with filler words. These fillers were also common six-letter words; 16 were chosen to comprise a 12-trial practice list and 48 were chosen to serve as mismatches for the experimental words on different trials, as shown in Table 1. Twelve additional pairs of fillers were selected to provide the majority of the different trials in the experiment.

Six case-mixture conditions were used, as shown in Table 2. These included intact (all upper and all lower case) and alternate (a case transition between every pair of letters) conditions. Three conditions had a single case transition after the second, third, or fourth letter of the words (2-4, 3-3, and 4-2 conditions, respectively). In a final condition, case transitions occurred after every pair of letters (2-2-2).

All stimuli were typed onto white $6 \times 9$ in. $(15.2 \times 22.9 \mathrm{~cm})$ index cards with an IBM Selectric typewriter for presentation in an Iconix four-field tachistoscope. From the subjects' viewport, a word subtended a vertical visual angle of $.2^{\circ}$ and a horizontal angle of $.8^{\circ}$. In order to minimize gross visual peculiarity for the case mixtures, typefaces were chosen so that the heights of the capitals were approximately the same as nonascending, nondescending lowercase letters. The typefaces were IBM's Prestige Elite for upper case and Letter Gothic for lower case.

The test sequences consisted of a 12-trial practice list, administered to all subjects, and one of the 12 180-trial experimental sequences, which differed for each subject. Six of the experimental sequences were constructed from one set of experimental words, and six were constructed from the other set. Of the 180 trials, 96 were experimental trials and the remaining were filler items. The overall ratio of same trials to different trials was 3:1. Across the experiment as a whole, every stimulus item, both experimental words and fillers, appeared equally often in all six case alternation conditions. The presentation order of all conditions within each sequence was randomized.

Procedure. Six male and six female introductory psychology students served as subjects. All were right-handed and reported normal vision. A 13th subject was dismissed for an excessive error rate $(12.5 \%)$.

The subjects were told that they would judge a sequence of 192 successively presented pairs of words which, when different, would differ by a pair of adjacent letters. They were also told that the words might be printed in upper or lower case (mixed case was not mentioned), but decisions were to be made without regard to case. They were informed that RT was being measured and that their responses were to be made as rapidly and accurately as possible.

Between trials, the subjects viewed a fixation rectangle, $2 \mathrm{~cm}$ wide $\times 1.3 \mathrm{~cm}$ high $\left(1.3^{\circ} \times .8^{\circ}\right.$ of visual angle), which surrounded the area in which the stimuli were displayed. After an audible signal from the experimenter, the subject initiated the presentation sequence by depressing a footswitch. The fixation box remained in view from $200 \mathrm{msec}$ and was followed by the first member of the word pair (always an intact upper- or lowercase word) for $500 \mathrm{msec}$. This was followed by a masking field consisting of three rows and six columns of overlapped Xs and Os for $800 \mathrm{msec}$ and the second member of the word pair for $300 \mathrm{msec}$. The second word, when intact, was never the same case as the first word, precluding rapid matches based on physical identity. Following offset of the second word, the fixation box returned until the beginning of the next trial. The subject signaled his response by pushing one of two response levers. All subjects indicated same responses with their preferred hands and different responses with the other hand.

\section{Results}

The data of primary interest are mean RTs on same trials for the experimental words. These data are presented in Figure 1, along with the overall mean RT for different trials involving the experimental words. The RT for same trials ${ }^{2}$ were sub- mitted to a two-factor, within-subjects analysis of variance, with Syllable Structure of the display and Case-Alternation Conditions as the two factors. Both main effects were significant: Syllable Structure, $F(3,33)=3.57, p<.05$, and Case Alternation, $F(5,55)=5.35, p<.001$. Multiple comparison contrasts revealed that one-syllable words were judged significantly faster than two-syllable words, $F(1,33)=6.86, p<.013$. Words presented in the intact condition were judged significantly faster than words containing one or two case transitions, $F(1,55)$ $=12.58, \mathrm{p}<.001$. These conditions, in turn, were significantly faster than the alternate condition, $F(1,55)=8.05, p<.006$. The interaction of Syllable Structure by Case Alternation condition was not significant, $\mathrm{F}<1$.

Spoehr and Smith (1973) have argued that an alternative syllable-like unit, the vocalic center group (VCG), is the relevant unit in word processing. Using the rules for VCG parsing given in Smith and Spoehr (1974), the experimental words were repartitioned post hoc into VCG groups whose structures corresponded to the original syllable classifications, and a reanalysis of the data was performed. The resulting RT trends were indistinguishable from the previous results, with the exception that the main effect difference between one- and two-VCG words was not significant $(\mathrm{p}>.25)$.

Error rates were very low and uniformly distributed across conditions. The mean error percentages for the experimental words on same and different trials were $1.5 \%$ and $3.8 \%$, respectively.

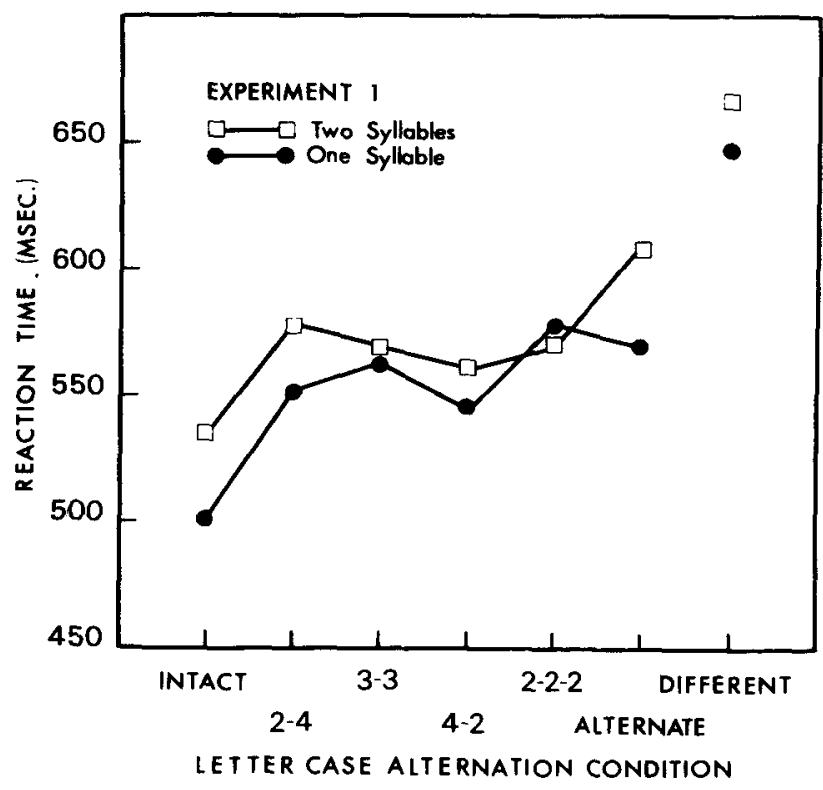

Figure 1. Reaction time data for same decisions for the oneand two-syllable experimental words in Experiment 1. Mean reaction time for different decisions involving the experimental words is shown for comparison purposes. 


\section{Discussion}

The data indicate the possibility of two levels of perceptual unit categories effective in this task, whole-words and spelling patterns. The RT decrement for words with a single case transition relative to intact words supports the prediction for wholeword units. Additionally, the nearly linear decrement in RT with increasing case transitions from one to five (most clearly shown in Figure 2) implies that spelling patterns were also functional visual units. The conclusion is not unreasonable. Dividing some processing attention over units of different sizes provides a capability for recognizing a display based on smaller units when the larger units fail to provide a basis for recognition.

There was no evidence that syllables were functional visual units. Performance was no better when case transitions occurred at syllable boundaries than when the transitions occurred within syllables. Although there was a significant main effect for syllables under conventional syllabification, this effect proved unreliable for the VCG analysis.

\section{EXPERIMENT 2}

The purpose of Experiment 2 was to extend the functional unit analysis to pronounceable nonwords (pseudowords). When perceptual recognition of words and pseudowords is compared, an advantage for words is frequently found (Juola, Leavitt, \& Choe, 1974; Manelis, 1974; McClelland, 1976). This "word superiority effect" has sometimes been invoked as evidence for whole-word perceptual units (Juola et al., 1974; Bruder, Note 1). However, the word superiority effect could have a number of loci in addition to the hypothesized use of whole-word units in early visual processing. For this reason, it is important to compare the effects of case alternations on the perception of both words and pseudowords. If the primary determinant of the word superiority effect were whole-word visual units, then the word superiority effect should hold only for intact displays. However, failure to eliminate the word superiority effect with case mixtures would not necessarily invalidate the logic of whole-word units, but rather imply that word familiarity has effects on other processes in addition to visual perceptual processes. Since whole-word units cannot exist for pseudowords, evidence for the use of whole-word units in Experiment 2 would be provided by a significantly greater word superiority effect for the intact condition relative to the case mixture conditions.

In Experiment 2, we sought not only to determine the functional visual units for processing words and pseudowords, but also to compare possible perceptual strategy effects for word and pseudoword processing. This was done by varying the experi- mental context for three groups of subjects. For each of the three groups, the experimental word and pseudoword pairs were the same, but they were embedded among different sets of filler items. It was hypothesized that a group judging mostly words would be most likely to adopt whole-word processing strategy, whereas a group judging mostly pseudowords would not. If differences in processing strategies are manifested by the use of different perceptual units, then this should be reflected by a smaller intact word superiority effect as the proportion of pseudoword trials increases.

\section{Method}

Stimulus materials. As in Experiment 1, two sets of experimental stimuli were selected. Each set consisted of 12 words (four one-syllable words, four two-syllable words with $2-4$ syllable structure, and four two-syllable words with 4-2 syllable structure) selected from among the words used in Experiment 1. Pseudowords were derived from these words by re-pairing the syllables of the two-syllable words and changing a letter in the one-syllable words (see Table 1). As in the first experiment, a filler different item was chosen for each experimental stimulus, and 21 pairs of filler words and 21 pairs of filler pseudowords were also selected.

For Experiment 2, four case mixture conditions, as shown in Table 2, were used. These included (1) zero-case transitions (intact upper or lower case), (2) one-case transition (3-3), (3) twocase transitions (2-2-2), and (4) three-case transitions (1-2-2-1).

Each of the 12 words and 12 pseudowords were used on same trials in all four case-alternation conditions for every subject. To these 96 experimental trials were added appropriate filler trials to create three kinds of experimental contexts. For Group 1 , the fillers were primarily words such that $75 \%$ of the 300 total trials were word pairs. For Group 2, equal numbers of word and pseudoword fillers were added to the experimental stimuli such that the 288-trial sequence was composed of $50 \%$ words and $50 \%$ pseudowords. For Group 3, 25\% of the 300-trial sequence was words and $75 \%$ was pseudowords. Eight sequences were constructed for each group, four being made up from each set of stimuli. In all cases, the first third of a sequence was filler items, thereby providing approximately 100 practice trials. For all sequences, the ratio of same to different trials was approximately $3: 1$.

Procedure. A total of 24 introductory psychology students, 11 males and 13 females, were randomly assigned to the groups, 8 subjects per group. One subject was replaced for an excessive error rate $(15.6 \%)$. The instructions and procedure were similar to those in Experiment 1. A change in equipment to an Iconix three-channel tachistoscope necessitated some modifications in exposure parameters and the use of a dark fixation field. Four dimly illuminated points defining the corners of a rectangle were provided as a fixation box. Two hundred milliseconds after the subject initiated a trial, the first member of the pair was illuminated for $3 \mathrm{sec}$, followed by the masking field for $800 \mathrm{msec}$, after which the second item was exposed for $1 \mathrm{sec}$ or until the subject responded. Both stimuli were typed in the case-alternation condition appropriate for the trial. Corresponding letters in the two strings were typed in different cases.

\section{Results}

Figure 2 presents the mean RT data for the three groups of subjects in Experiment 2, as well as the data from Experiment 1 for comparison. As before, only the RT data from same trails for the experi- 
Table 1

Examples of the Words Serving as Stimuli for Experiments 1, 2, and 3

One Syllable Words
TOWARD (UPWARD)
MARKED (MILKED)
CHANCE (CHOICE)
RIGHTS (RIGORS)
FRENCH (FRENZY)
GROUND (GROUCH)

\begin{tabular}{lll} 
& \multicolumn{2}{c}{ One Syllable Words } \\
\cline { 2 - 3 } Words & RIGHTS & (RIGORS) \\
& TOWARD & (UPWARD) \\
& FRENCH & (FRENZY) \\
& MARKED & (MILKED) \\
& BIGHTS & (BIGORS) \\
Pseudowords & LOWARD & (HUWARD) \\
& GRENCH & (GOONCH) \\
& TARKED & (TILKED)
\end{tabular}

\begin{tabular}{|c|c|c|c|}
\hline & & Two Sy & le Words \\
\hline OME & (INCOME) & NOR $\cdot M A L$ & (DERMAL) \\
\hline IT - SELF & (MYSELF) & MAR·KET & (MUSKET) \\
\hline $\mathrm{JU} \cdot \mathrm{NIOR}$ & (SENIOR) & TRY $\cdot$ ING & (TAKING) \\
\hline DE-GREE & (DEFACE) & CAN·NOT & (CARROT) \\
\hline EX·PECT & (EXPORT) & SIM-PLE & (SINGLE) \\
\hline $\mathrm{RE} \cdot \mathrm{CENT}$ & (RECEDE) & VAL·UES & (VALETS) \\
\hline
\end{tabular}

Experiment 2

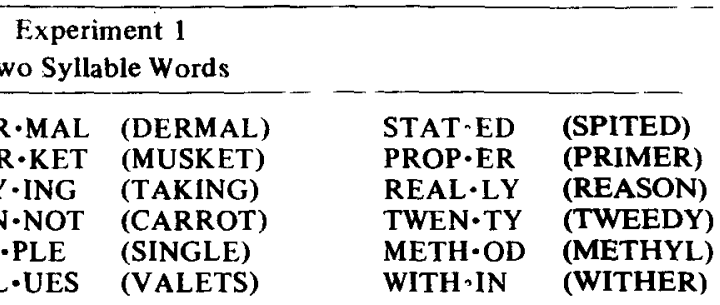

Two Syllable Words

\begin{tabular}{|c|c|c|c|}
\hline $\begin{array}{l}\text { EX·PECT } \\
\text { RE·CENT } \\
\text { DE-GREE } \\
\text { IT-SELF }\end{array}$ & $\begin{array}{l}\text { (EXPORT) } \\
\text { (RECEDE) } \\
\text { (DEFACE) } \\
\text { (MYSELF) }\end{array}$ & $\begin{array}{l}\text { WITH·IN } \\
\text { PROP } \cdot \text { ER } \\
\text { STAT·ED } \\
\text { METH·OD }\end{array}$ & $\begin{array}{l}\text { (WITHER) } \\
\text { (PRIMER) } \\
\text { (SPITED) } \\
\text { (METHYL) }\end{array}$ \\
\hline $\begin{array}{l}\text { EX-GREE } \\
\text { RE-SELF } \\
\text { DE-PECT } \\
\text { IT-CENT }\end{array}$ & $\begin{array}{l}\text { (EXGLOE) } \\
\text { (RESERM) } \\
\text { (DENOCT) } \\
\text { (MOCENT) }\end{array}$ & $\begin{array}{l}\text { WITH•OD } \\
\text { PROP·ED } \\
\text { STAT·IN } \\
\text { METH•ER }\end{array}$ & $\begin{array}{l}\text { (WITHEM) } \\
\text { (PREMED) } \\
\text { (SOLTIN) } \\
\text { (METHUS) }\end{array}$ \\
\hline
\end{tabular}

Experiment 3 Pseudowords Nonwords

\begin{tabular}{l}
\multicolumn{1}{c}{ Words } \\
\hline HANDS LANDS \\
GIANT GRANT \\
DRANK DRINK \\
THEME THERE \\
SPEND SPENT
\end{tabular}

HSNDA LSNDA
GTNIA GTNRA
RDNKA RDNKI
EEMHT EERHT
EDNSP ETNSP

Note-Items listed here comprise one-half the total stimulus pool. The other half was chosen to have similar characteristics. Items enclosed in parentheses are filler items chosen to serve on different trials.

mental stimuli were analyzed. The mean different RT for the experimental stimuli are plotted simply for comparison purposes. The error rate for the experimental stimuli was quite low and unsystematically distributed among the conditions. For Groups 1,2 , and 3, the error rates were $.4 \%, 1.0 \%$, and $1.7 \%$, respectively. ${ }^{3}$

Experiment 2 was a one-between- and three-withinsubjects design. Context Group was the betweensubjects factor. The within-subjects factors were Stimulus Type (word or pseudoword), Case-Alternation Condition, and Syllable Structure. The main effects of Context Group, $F(2,21)=5.23, \mathrm{p}<.014$, Stimulus Type, $F(1,21)=39.01, p<.001$, and Case-Alternation condition, $F(3,63)=4.73, p<.005$, were significant. The interaction of Stimulus Type by Context Group was only marginally significant, $\mathbf{F}(2,21)=3.31$, $p<.055$. There were no significant main effects or interactions involving Syllable Structure (all Fs $<1$ ).

Pairwise comparisons of the means underlying the significant main effects were made with the Tukey $B$ test at $a=.05$. Following convention, underscores indicate sets of means that did not differ significantly, and means not grouped by a common underscore were significantly different. For context groups, the means ordered as follows: Group 1 Group 2 Group 3. The The case alternation conditions ordered as follows: Zero One Two Three. Simple main effects tests of stimulus type for each context group revealed that word judgments were significantly faster than pseudoword judgments for all three groups; Group 1, $F(1,7)=12.56, p<.009$; Group $2, F(1,7)=12.81$, $\mathrm{p}<.009$; Group 3, F(1,7) $=20.56, \mathrm{p}<.003$.

\section{Discussion}

Not only do the data indicate an essentially linear increase in RT with number of case transitions for both words and pseudowords, but the magnitude of the word superiority effect is about the same in all conditions. These results suggest that spelling patterns were effective visual units for both words and pseudowords. Although the ratio of words to pseudowords was manipulated among the three

Table 2

Examples of the Case Mixture Conditions Used in Experiments 1, 2, and 3

\begin{tabular}{|c|c|c|c|c|c|}
\hline \multicolumn{5}{|c|}{ Experiment 1} & \multirow[b]{2}{*}{ Alternat } \\
\hline Intact & $2-4$ & $3-3$ & 4-2 & $2-2-2$ & \\
\hline RIGHTS & RIghts & RIGhts & RIGHts & \multirow[t]{2}{*}{ RIghTS } & $\overline{\operatorname{RiGhT}} \overline{\mathrm{s}}$ \\
\hline \multicolumn{5}{|c|}{ Experiment 2} & \\
\hline Zero & & One & Two & & Three \\
\hline $\begin{array}{l}\text { french } \\
\text { GRENCH }\end{array}$ & & $\begin{array}{l}\text { freNCH } \\
\text { GREnch }\end{array}$ & $\begin{array}{l}\text { frENch } \\
\text { GRenCH }\end{array}$ & & $\begin{array}{l}\text { fREnch } \\
\text { GreNCh }\end{array}$ \\
\hline \multicolumn{6}{|c|}{ Experiment 3} \\
\hline Zero & & \multicolumn{2}{|c|}{ Two } & \multicolumn{2}{|c|}{ Four } \\
\hline \multicolumn{2}{|c|}{$\begin{array}{l}\text { HANDS } \\
\text { shand } \\
\text { HSDNA }\end{array}$} & \multicolumn{2}{|c|}{$\begin{array}{l}\text { HandS } \\
\text { sHANd } \\
\text { HsndA }\end{array}$} & \multicolumn{2}{|c|}{$\begin{array}{l}\text { HaNdS } \\
\text { sHaNd } \\
\text { HsNdA }\end{array}$} \\
\hline
\end{tabular}




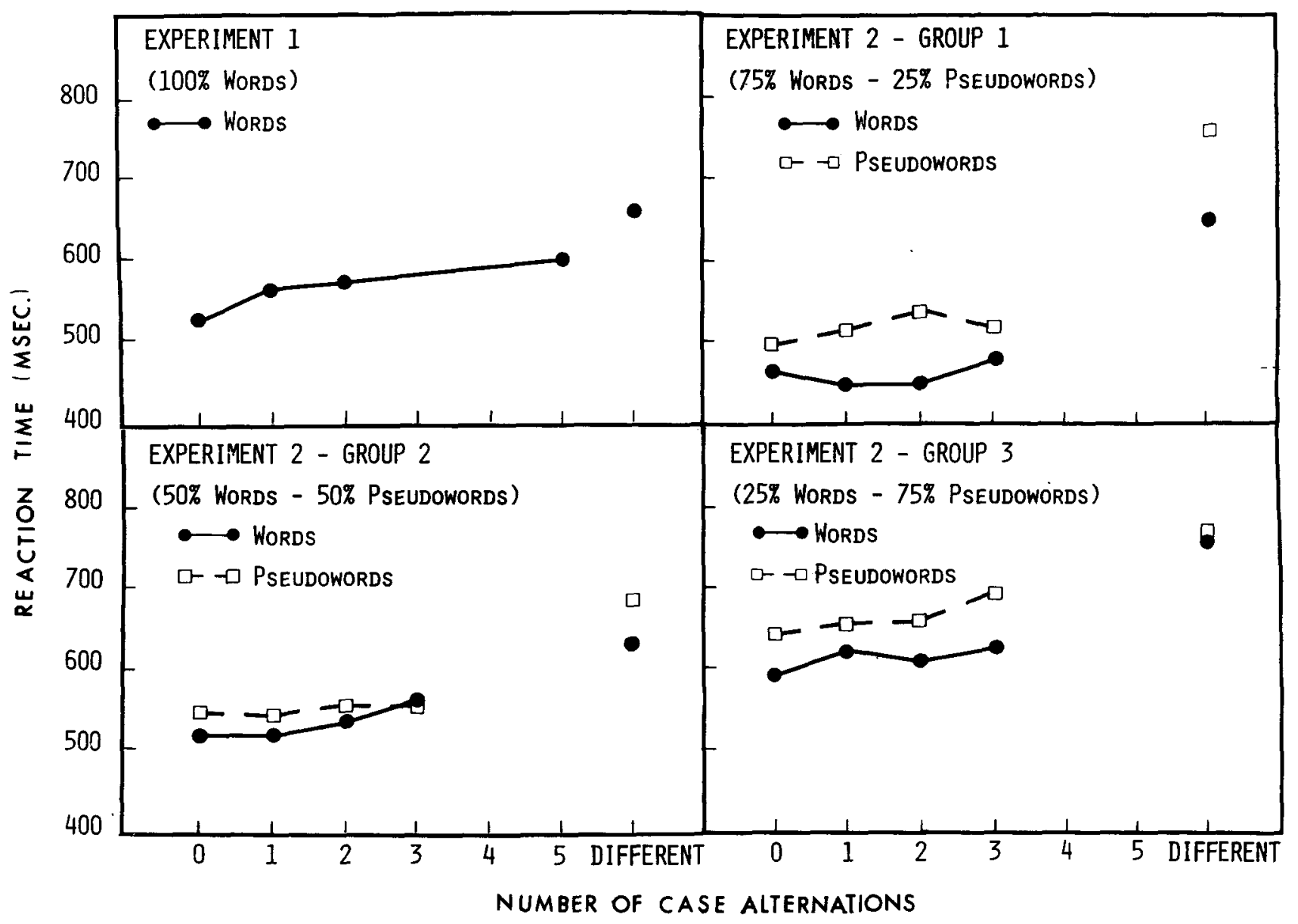

Figure 2. Reaction time to make same decisions for Experiment 1 and for the three groups of Experiment 2. Mean reaction times for different decisions involving the experimental stimuli is shown in each panel.

groups, there was no evidence that this produced a differential tendency to process whole-word units. The significant word superiority effect for all three groups is particularly interesting, since the functional visual unit analysis is insufficient to explain this result. The word advantage was uninfluenced by case mixtures, implying that this advantage occurred at a processing stage or stages other than the ones which are affected by case mixtures. If it is assumed that processing proceeds from early form-specific stages to later more abstract stages, then this word advantage must occur after visual recognition when whole words, spelling patterns, and single letters have influence as visual units. The large main effect of experimental context probably reflects the difficulty of judging mostly pseudoword trials compared to judging mostly word trials. This effect might be attributable to differences in speed-accuracy criteria adopted by the three groups in order to maintain low error rates as demanded by the instructions.

The observation that syllables were not functional units was also reaffirmed. The stimuli for Experi- ment 2 were selected from among the stimuli of Experiment 1 for which VCG and dictionary syllable structures were the same. Careful examination of the case alternation conditions for which case transitions occurred between syllables vs. within syllables failed to find any reliable trend indicating that case transitions within syllables caused greater processing difficulty than when the case transitions fell between syllables.

\section{EXPERIMENT 3}

Experiments 1 and 2 produced results consistent with the hypothesis that case alternations within words and pseudowords hinder perception by disrupting multiletter perceptual units. However, these results could be accounted for merely by assuming that processing is sensitive to the number of case transitions regardless of their placement. The inclusion of nonword strings in Experiment 3 provides a test of the assumption that case transitions between perceptual units have a negligible effect on percep- 
tual processing. Nonwords have minimal sequential redundancy and should be processed at the level of individual letters. Therefore, nonword processing should be unaffected by lettercase mixtures.

A second objective of Experiment 3 was to provide a further test for the existence and use of wholeword perceptual units. Experiment 2 found no evidence for a greater word superiority effect between intact words and pseudowords than between mixed case words and pseudowords when these trial types were randomly intermixed. Word, pseudoword, and nonword trials were blocked in Experiment 3, with the expectation that the use of wholeword units would be more likely when words were expected on every trial in a block.

Several procedural changes were made in the design of Experiment 3. The most significant of these were the use of simultaneous presentations rather than successive presentations of the stimulus pairs and the use of the experimental stimuli for both same and different decisions. Simultaneous presentation was used to minimize possible memory differences between words, pseudowords, and nonwords that might generate artifactual differences in response times. Testing the stimuli in all conditions under both same and different decisions also provided a comparison of the results of mixing cases on both decision types.

\section{Method}

Stimulus materials. Ten pairs of common five-letter words (two sets of five pairs each) were selected from the Kučera and Francis (1967) count so as to meet the following constraints: (1) The words in each pair differed by only a single letter, and within each set this difference occurred once at each of the five serial positions. (2) The words in each set were relatively uniform in frequency (mean frequency of $263 /$ million). (3) No word contained more than one letter whose visual form was similar in both upper- and lowercase print, such as c, s, o, etc. (4) The lowercase letter forms for the critical letters in every pair were matched so that they were both ascenders, both descenders, or both middle-sized letters; i.e., hands-lands but not hands-sands. (5) Each pair within a set could be anagrammed into a pseudoword and a nonword while still maintaining a critical letter at each serial position in the derived sets of pseudowords and nonwords. Anagrams of candidate word pairs were submitted to six colleagues who rated them for pronounceability. The anagrams rated as most pronounceable were selected for use as pseudowords, and the least pronounceable were used as nonwords (see Table 1).

The following three case-alternation conditions were employed: (1) zero alternations (intact upper or lower case); (2) two alternations (1-3-1); and (3) four alternations (odd letters in one case, even letters in the other) (see Table 2). Unlike Experiments 1 and 2, each stimulus word was used once in every alternation condition as a same trial and once as a different trial. Since the different trial occurrences included both members of a pair, this was counted as the different occurrence for both members. Thus the ratio of same trials to different trials was $2: 1$.

The stimulus pairs were typed onto cards, as in Experiments 1 and 2. The two strings were arrayed one above the other. Each string subtended a visual angle of $.5^{\circ}$ in width $\times .2^{\circ}$ in height, with $.4^{\circ}$ vertical separation between the two strings. For all pairs, letters in corresponding serial positions were in opposite cases (e.g., BegiN-bEGIn). For a randomly chosen half of all pairs, the initial letter of the upper string was in upper case; for the remaining half, it was in lower case.

Twelve 270-trial sequences were constructed. The first 135 trials of each were used as practice trials and the second as experimental trials. For six subjects' sequences, one set of stimulus pairs served in the practice trials and the remaining set served in the experimental trials. For the other six subjects' sequences, this assignment was reversed.

The 135-trial sequence halves were similarly constructed. Each consisted of three blocks of 45 trials: one block of word pairs, one block of pseudoword pairs, and one block of nonword pairs. Within each block, the 10 same pairs and 5 different pairs occurred once in each of the three case-alternation conditions, randomly ordered. The presentation order of the three blocks was randomized for each subject.

Procedure. Twelve introductory psychology students, $10 \mathrm{fe}-$ males and 2 males, served as subjects. All reported normal or corrected-to-normal vision.

The subjects were told that they would make same-different judgments for simultaneously presented five-letter words, pseudowords, or nonwords, which, when different, would differ by a single letter. They were told that some pairs would be typed in mixtures of upper- and lowercase letters, but that they were to make their decisions without regard to case.

Each trial began with an audible warning tone. The subject then depressed a footswitch initiating the trial. A gray rectangular fixation box $\left(1.4^{\circ}\right.$ wide $\times .8^{\circ}$ high) remained in view for $500 \mathrm{msec}$ and then was replaced by the stimulus pair. The stimulus pair was displayed until a response was made or $1,500 \mathrm{msec}$ had elapsed. In either case, the fixation field returned during the intertrial interval. The subject indicated his response by pressing one of two buttons with his preferred hand (right hand for 11 of 12 subjects) for a same judgment. The other button was pressed with the other hand for a different response. The subjects were instructed to respond as rapidly as possible without making errors. At the beginning of each block, the subject was told the type of pairs he was to judge during the block. The entire session lasted approximately $1 \mathrm{~h}$.

\section{Results}

The RT data are presented in Figure 3 and the error data in Table 3. The RT data were submitted to a three-factor, within-subject analysis of variance with the factors being Decision Type (same vs. different), Stimulus Type (word, pseudoword, or nonword), and Alternation Condition (zero, two, or four). The main effects of Stimulus Type, $F(2,22)=$ $45.20, p<.001$, and Alternation Condition, $F(2,22)$ $=6.81, \mathrm{p}<.005$, were significant; but the main effect of Decision Type was not, $F(1,11)=1.09$, $\mathrm{p}>.25$. While words were clearly judged faster than pseudowords, and pseudowords faster than nonwords, case alternations appear to have affected same decisions but not different decisions. This was attested to by the marginally significant interactions of Decision Type with Alternation Condition, $F(2,22)=2.45, p<.108$, and of Decision Type with Stimulus Type with Alternation Condition, $F(4,44)=1.86, p<.134$.

There were differences between same and different judgments not only in their RT trends, but on their error rates as well. When the error percentages were submitted to a three-factor analysis of variance it was found that different decisions had a significantly higher error rate than same decisions, $F(1,11)$ 


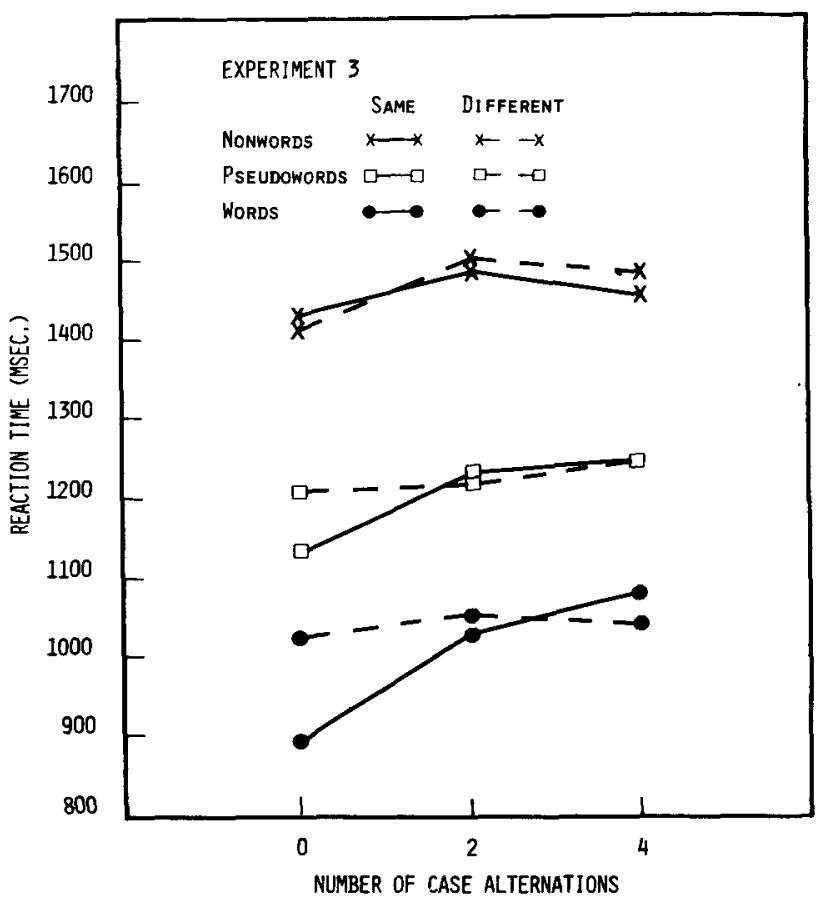

Figure 3. Reaction time to make same-different judgments for simultaneously presented five-letter words, pseudowords, and nonwords.

$=31.05, p<.001$. Both the main effect of Stimulus Type, $F(2,22)=10.21, p<.001$, and the interaction of Stimulus Type with Decision Type, $F(2,22)$ $=4.91, \mathrm{p}<.017$, were significant. There was no effect of stimulus type on error rates for same judgments (simple main effect $F<1$ ), but error rates increased significantly from word to pseudoword to nonword displays for different judgments [simple main effect $F(1,22)=15.99$, $p<.001]$. There was no effect of alternation condition on error rates, $\mathrm{F}(2,22)=2.05, \mathrm{p}>.15$.

Because of the marginally significant differences in RT trends and the large differences in error rates between same and different decisions, the RT data for the two decision types were submitted to separate analyses of variance. Both were two-factor, withinsubjects designs, with the factors being Stimulus Type and Alternation Condition. These analyses confirmed that case alternations only affected same decisions. For same RTs, the effects of Alternation Condition, $F(2,22)=19.96, p<.001$, and its inter-

Table 3

Error Percentages for Experiment 3

\begin{tabular}{|c|c|c|c|c|c|c|}
\hline \multirow[t]{3}{*}{ Stimulus Type } & \multicolumn{3}{|c|}{ Same Judgments } & \multicolumn{3}{|c|}{ Different Judgments } \\
\hline & \multicolumn{6}{|c|}{ Number of Case Alternations } \\
\hline & 0 & 2 & 4 & 0 & 2 & 4 \\
\hline /ords & 0.0 & 17 & $4 . \overline{2}$ & 6.7 & 6.7 & 10.0 \\
\hline Pseudowords & 25 & 0.0 & 3.3 & 11.7 & 15.0 & 13.3 \\
\hline Vonwords & 17 & 2.5 & 5.0 & 20.0 & 18.3 & 26.7 \\
\hline
\end{tabular}

action with Stimulus Type, $F(4,44)=6.87, \mathrm{p}<.001$, were significant. For the different RTs, the casealternation condition and its interaction with stimulus type both produced Fs $<1$.

To test for the use of whole-word units, the planned comparison ${ }^{4}$ between intact words and pseudowords and mixed case words and pseudowords was made. This contrast revealed that for same decisions the word superiority effect was significantly greater for the intact condition than for the mixed-case conditions, $F(1,44)=4.47, p<.038$.

\section{Discussion}

The suggestion from Experiment 1 that wholeword units are functional when the display routinely consists of common words was substantiated by the larger word superiority effect for intact displays than for mixed case displays. By presenting only words in a block of trials, it would appear that the subjects were encouraged to use whole-word units. A similar conclusion was reached by Manelis (1974), who found a greater perceptual advantage for words over pseudowords with blocked presentations.

The slight, and nonsignificant, effect of case mixture on nonword strings substantiates the prediction that nonwords should be unaffected by case alternations. Nonwords, which possess very few multiletter perceptual units, should be unaffected by the introduction of letter-case transitions because the individual letters in the string are the functional visual units.

The finding that different decisions were unaffected by case mixture was an unexpected result, although not altogether surprising. It is not uncommon for different judgments in the samedifferent decision task to show trends which differ from those for same judgments (Krueger, 1975). There is no generally accepted explanation for this result, but it is frequently proposed that same and different decisions are mediated by different processes (e.g., Bamber, 1969). We have assumed, as have others (e.g., Henderson \& Chard, 1976), that samedifferent RT is primarily a reflection of perceptual recognition time. We still believe that this is the case for same responses.

\section{GENERAL DISCUSSION}

The results of the three experiments can be briefly summarized by noting that there were large and reliable superiority effects for words over pseudowords and nonwords and that case alternations significantly disrupted same judgments for words and pseudowords only. These results corroborate the findings of several recent studies reporting the effects of visual disruptions on the perception of letter strings.

Travers $(1973,1974)$ introduced temporal dis- 
ruptions in visual displays by presenting portions of words ranging from four to eight letters in length in a rapid left-to-right serial order. He found that sequential presentation of the individual letters of the words, with appropriate masking to reduce visual persistence, resulted in a markedly reduced ability to report the words relative to display conditions in which the entire word was presented simultaneously. Travers (1974) found that when successive letter pairs were presented in sequential order, performance was substantially improved, and when trigrams were presented, performance was not significantly different from the simultaneous condition. Although Travers' procedure differed considerably from the procedure employed here, his results are consistent with our case-mixture results. The sequential presentation of single letters is a temporal analog of the case alternate condition and correspondingly resulted in the largest performance decrement. Simultaneous presentation of bigrams and larger n-grams permitted functioning of multiletter perceptual units, resulting in improved recognition.

Our use of case mixtures to disrupt visual processing is similar to studies reported by McClelland (1976) and Pollatsek, Well, and Schindler (1975). Pollatsek et al.'s (1975, Experiment 1) procedure was very similar to the procedure in Experiment 3. Their subjects made same-different decisions for pairs of simultaneously presented four-letter words and unpronounceable nonwords printed with zero through three letter-case alternations. They found that words were always judged faster than nonwords and that nonwords were only weakly affected by case mixtures whereas words were strongly affected. Two aspects of Pollatsek et al.'s results were particularly significant for our conclusions. The first was the minimal effect of case alternation on nonwords. This supports the assertion that individual letters are the functional visual units for nonwords, resulting in essentially no effect of case mixtures. The second finding was a markedly greater RT decre-ment with the introduction of the first case transition in a word than for each subsequent case transition. This result parallels a similar finding in Experiments 1 and 3 which has been interpreted as implying that whole words may be functional visual units.

McClelland's (1975) study shares many common features with the present study and provides several interesting comparisons. McClelland presented fourletter words, pseudowords, and nonwords (random letter strings) to subjects in a forced-choice recognition paradigm. His stimuli were printed in either an intact upper- or lowercase typeface or alternating occurrences of upper- and lowercase letters. He found that recognition was best for words, next best for pseudowords, and worst for nonwords. Words and pseudowords showed similar decrements in recognition for mixed-case relative to intact presentations. For nonwords, however, recognition performance was the same in both intact and case-alternate conditions. Comparing those conditions in the present study which most closely replicate McClelland's, the trends are in complete agreement. These casemixture effects are strikingly reliable considering the significant procedural differences between the two studies. Although McClelland interpreted his data as suggesting that preliminary letter identification is followed by the utilization of word-specific and general orthographic redundancy yielding a word superiority effect, we believe that the casemixture data suggest the utilization of multiletter and perhaps whole-word perceptual units in the early stages of visual processing. The large overall word superiority effects in both studies suggest that knowledge of orthographic structure and wordspecific knowledge play an additional role in later stages of visual perception and/or postperceptual processing.

Two final aspects of the data deserve comment. The first was the absence of case-mixture effects on different responses in Experiment 3. Although this seems to suggest a locus for case-mixture effects in post perceptual comparison or response selection stages, such an explanation would be inadequate to account for the results of the other studies cited; for example, Travers' (1974), which required no explicit comparison process. The similarity of results in the various studies cited seems to imply a locus in perceptual processes common to same-different, whole report, and forced-choice recognition tasks.

Secondly, the role of processing strategies in word perception was not adequately resolved by the present data. Although the variation of experimental context in Experiment 2 induced main effect changes in RT, and differences were found between blocked presentation in Experiment 3 and mixed presentation in Experiment 2, no specific effects of context and processing strategies on functional visual units were directly revealed by these manipulations. However, the indirect indications of differences revealed by the present study and the others discussed here suggest a need for more scrutiny of strategy effects on perception.

By assuming that perceptual units consist of interdependently processed letters, it has been possible to use mixed letter-case displays to discover functional perceptual units in word recognition. The underlying assumption received support from the lack of casemixture effects on nonword strings but pronounced effects on words and pseudowords. The results indicated that syllables are not functional visual units. Spelling patterns are functional visual units for processing words and pseudowords, and whole-word units might also be functional units, although their 
utilization appears to depend on situational context and subjects' expectancies. Our results are consistent with the hypothesis that several levels of perceptual units exist for recognizing words and other letter strings, and the level that is activated by incoming visual information can depend on what is expected as well as what is present in the display.

\section{REFERENCE NOTE}

1. Bruder, G. A. Effect of unfamiliar form on physical matches of words and nonwords. Paper presented at the annual meeting of the Psychonomic Society, Denver, November 1975.

\section{REFERENCES}

Aderman, D., \& Smith, E. E. Expectancy as a determinant of functional units in perceptual recognition. Cognitive Psychology, $1971,2,117-129$.

BAMBER, D. Reaction time and error rates for "same-different" judgments of multidimensional stimuli. Perception \& Psychophysics, 1969, 6, 169-174.

Clarr, H. H. The language-as-fixed-effect fallacy: A critique of language statistics in psychological research. Journal of Verbal Learning and Verbal Behavior, 1973, 12, 335-359.

EsTES, W. K. The locus of inferential and perceptual processes in letter identification. Journal of Experimental Psychology: General, 1975, 104, 122-145. (a)

Estes, W. K. Memory, perception, and decision in letter identification. In R. L. Solso (Ed.), Information processing and cognition: The Loyola symposium. Potomac, Md: Erlbaum, 1975. (b)

Henderson, L., \& Chard, J. On the nature of the facilitation of visual comparisons by lexical membership. Bulletin of the Psychonomic Society, 1976, 7, 432-434.

Juola, J. F., LeavitT, D. D., \& Choe, C. S. Letter identification in word, nonword, and single letter displays. Bulletin of the Psychonomic Society, 1974, 4, 278-280.

KRUEGER, L. E. Familiarity effects in visual information processing. Psychological Bulletin, 1975, 82, 949-974.

KuČera, H., \& Francis, W. N. Computational analysis of present-day American English. Providence: Brown University Press, 1967.

LaBerge, D., \& Samuels, S. J. Toward a theory of automatic information processing in reading. Cognitive Psychology, 1974, 6. 293-323.

Manelis, $L$. The effect of meaningfulness in tachistoscopic word perception. Perception \& Psychophysics, 1974, 16, 182-192.

MCClelland, J. L. Preliminary letter identification in the perception of words and nonwords. Journal of Experimental Psychology: Human Perception and Performance, 1976, 2, 80-91.

Pollatsek, A., Well, A. D., \& Schindler, R. M. Familiarity affects visual processing of words. Journal of Experimental Psychology: Human Perception and Performance, 1975, 1, 328-338.

Schindler, R. M., Well, A. D., \& Pollatsek, A. Effects of segmentation and expectancy on matching time for words and nonwords. Journal of Experimental Psychology, 1974, 103, 107-111.

SMIth, E. E., \& Spoenr, K. T. The perception of printed English:
A theoretical perspective. In B. H. Kantowitz (Ed.), Human information processing: Tutorials in performance and cognition. Potomac, Md: Erlbaum, 1974.

SMITH, F. Understanding reading. New York: Holt, Rinehart, \& Winston, 1971.

Spoehr, K. T., \& Smith, E. E. The role of syllables in perceptual processing. Cognitive Psychology, 1973, 5, 71-89.

TRAVERs, J. R. The effects of forced serial processing on identification of words and random letter strings. Cognitive Psychology, 1973, 5, 109-137.

Travers, J. R. Word recognition with forced serial processing: Effects of segment size and temporal order variation. Perception \& Psychophysics, 1974, 16, 35-42.

Webster's Seventh New Collegiate Dictionary. Springfield, Mass: Merriam, 1963.

\section{NOTES}

1. The decision to base the design of Experiments 1 and 2 soley on same responses was made for pragmatic reasons as well as for theoretical reasons. The additional constraint on stimulus selection necessary to have examined different decisions would have resulted in an overly restricted set of stimulus items. Also, completion of the design to allow same and different responses in all conditions would have necessitated more than doubling the already lengthy experimental sequences of Experiment 2. We hoped, therefore, not to sacrifice any important information by our exclusion of different decisions from the analyzable data.

2 . In order to ensure that the experimental results would generalize to both stimulus and subject populations (Clark, 1973), all three experiments employed self-replication as a basic research strategy. In each experiment, half of the subjects were tested on one set of stimulus materials and the remaining subjects on a second set. The initial step in data analysis was a preliminary analysis of variance including Replication as a factor in the design. This analysis was performed to determine if the pattern of results was dependent on specific combinations of stimuli and subjects. Although it is not possible to prove with this technique that no differences between replications exist, it was decided as a ruleof-thumb that reliable results had been obtained if no factor involving replications reached significance at the .25 level. We felt that the designs were sufficiently powerful that meaningful differences in trends would be detected with such a generous confidence level. The results of all three experiments were reliable by these standards; hence all reported results are based on data pooled across replications.

3. The overall error rates combining the experimental stimuli and fillers (including practice trials) were as follows: Group 1, sames $=4.1 \%$, differents $=7.5 \%$; Group 2 , sames $=2.1 \%$, differents $=5.7 \% ;$ and Group 3, sames $=2.0 \%$, differents $=5.1 \%$.

4. If the means underlying this interaction are represented with the mnemonics $W$ and $P$ for word and pseudoword and 0,2 , and $\mathbf{4}$ for the alternation conditions, then the contrast is (PO - WO) $-1 / 2[(P 2-W 2)+(P 4-W 4)]$.

(Received for publication January 14, 1977; accepted for publication February 14, 1977.) 